\title{
United States shifts focus to food marketing in battle to reduce childhood obesity
}

Published at www.cmaj.ca on June 8

$\mathrm{T}$ hree months after First Lady Michelle Obama launched a national crusade against childhood obesity in the United States, the government backed it up with a report packed with 70 recommendations on how to combat the problem and one audacious goal: reducing the childhood obesity rate from today's $20 \%$ to $5 \%$ by 2030 .

The recommendations in the White House Task Force on Childhood Obesity Report to the President start early - in the womb, in fact — with calls for better prenatal care and then encouraging breast-feeding. From there, they fan out broadly to target the foods children eat in school cafeterias, the availability of good food in underserved urban and rural areas, marketing by food manufacturers, nutrition labelling, efforts to promote biking and walking, and more (www.letsmove.gov /taskforce childhoodobesityrpt.html).

"We know we have the tools, we know we have the resources to make this happen," Obama said in announcing the report. "And now, thanks to the work of the task force, we have a road map for implementing our plan across our government and across the country." Still to come, the White House promises, is a strategy to implement the recommendations.

Childhood obesity experts say the report strikes all the right notes in calling for action by governments, schools, businesses, parents and food makers. But some experts says it is short on specifics and doubt the 5\% goal is attainable.

Dr. David Katz, director of Yale University's Prevention Research Center in New Haven, Connecticut, says that when obesity is being seen at ever younger ages and is increasing in severity, "to suggest that we're going to throw it into reverse and put a timeline on that is premature."

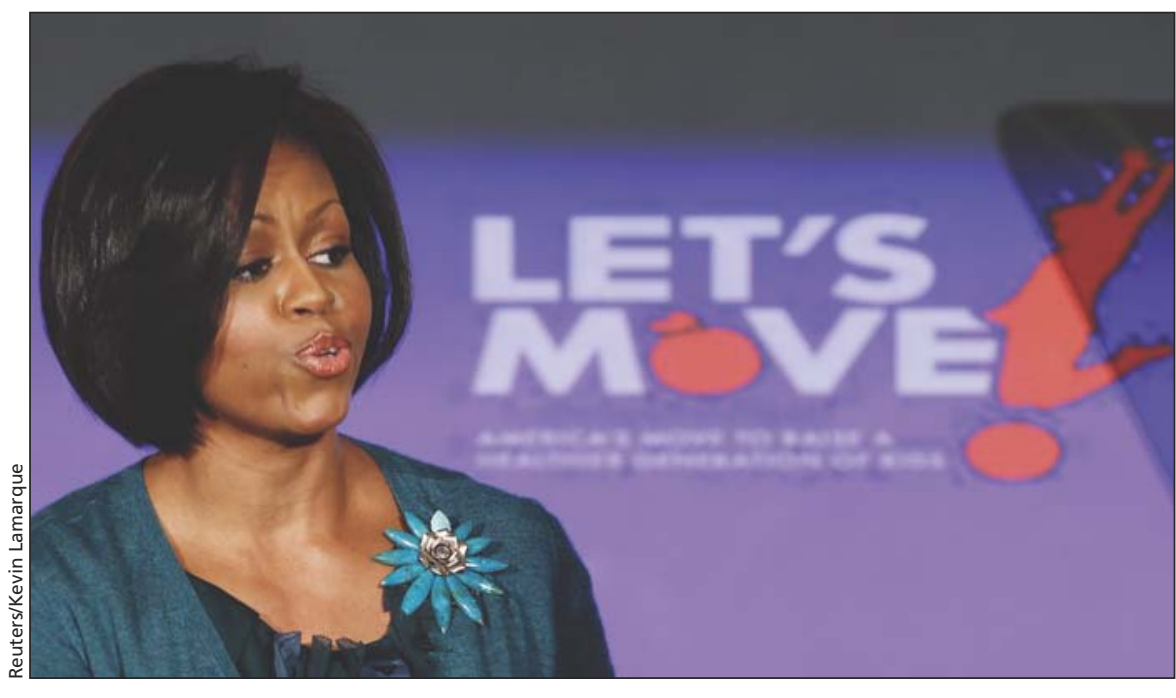

United States First Lady Michelle Obama unveils a nationwide campaign to combat childhood obesity, at the White House in Washington, DC, on Feb. 9.

The government estimates nearly one-third of US children are now overweight or obese, compared with about a quarter of Canadian children. But Katz says current definitions understate the problem, and estimates it would be more accurate to say that $50 \%$ of children in the US are overweight, with Canada not far behind.

The government's anti-obesity efforts are playing out at a time of growing public interest in healthy eating and weight loss, fueled by everyone from celebrity chefs such as Jamie Oliver and Rachel Ray to the advocacy group Corporate Accountability International, which is on a mission to get rid of Ronald McDonald, the icon of the fast-food maker McDonald's.

Katz says all the recent attention "tells us that something has changed. Everyone at least is looking at the issue."

But he worries that while there is growing recognition of the need to do something, progress could be hampered by the anti-government sentiment evident in the conservative "tea party" movement. The whole "I look out for myself" mindset, Katz says, could fore- stall progress on encouraging a broadbased push against obesity.

Food manufacturers, for their part, are trying to get out in front of the government's anti-obesity efforts by acting on their own. There's the threat of more government regulation if they don't.

For example, if task force recommendations for voluntary steps to limit marketing of less-healthy foods to children don't yield substantial results, the White House report says, the Federal Communications Commission "could consider revisiting and modernizing rules on commercial time during children's programming."

Less than a week after the May 10 release of the task force report, Obama was back before the cameras to help a coalition of food and beverage manufacturers announce a voluntary plan to cut 1.5 trillion calories out of their products by the end of 2015 by developing lower-calorie options and reducing portion sizes.

Obama called the pledge by the Healthy Weight Commitment Foundation "precisely the kind of private sector commitment we need." 
But while 1.5 trillion calories sounds like a hefty amount, it won't go very far toward getting 300 million Americans into skinny jeans.

It works out to fewer than 15 calories per person per day.

Marion Nestle, a professor of nutrition at New York University, says the White House report has too many recommendations - and too many of them seek only voluntary action - "but buried within them are some important ones about marketing to kids."

"The big shift is recognizing that obesity is not just about personal responsibility," she says. "It's about how food marketing and the food system affect personal health."

Dr. Walter Willett, chair of the department of nutrition at Harvard University's School of Public Health in Boston, Massachusetts, says that while the public seems to be coming around to the idea of doing more to combat child obesity, food manufacturers have pushed back hard against efforts to limit "the aggressive advertising of junk food to children, and that just has to stop if we are going to win" the obesity battle.
Katz says that while the US is the "epicenter of the global obesity epidemic," it also seems to have the most public focus on finding solutions. $\mathrm{He}$ said Canada's provincial health ministries have been particularly active but the country doesn't have an aggressive national strategy. Ultimately, though, Katz says, Canada could have better prospects for a coordinated solution because of its "more manageable population." - Nancy Benac, Washington, DC

DOI:10.1503/cmaj.109-3281 